\title{
Comparative Anatomy of Axial Skeleton of Red-eared Turtle (Trachemys scripta elegans, Wied 1838) and Softshell Turtle (Amyda cartilaginea, Boddaert 1770)
}

\author{
Hanif Mustafa ${ }^{1}$, Muhammad Ja'far Luthfi ${ }^{2 *}$, Fadhilatul Ilmi ${ }^{2}$, Ida Khoirunnisa ${ }^{2}$, Takrima ${ }^{2}$ \\ ${ }^{1}$ Biology Department, ${ }^{2}$ Biology Education Department, Faculty of Science and Technology, UIN Sunan Klijaga \\ Jl. Marsda Adisucipto No 1 Yogyakarta 55281, Indonesia. Tel +62-274-540971, Fax. +62-274-519739 \\ Email: Jafarluthfi@yahoo.com
}

\begin{abstract}
Red-eared turtle and softshell turtles belong Cryptodira Suborder which has a different characteristic in neck length and head movement. The aim of this study was to determine of the axial skeleton anatomical structure including vertebrae, carapace and plastron of the red-eared turtle (Trachemys scripta elegans Wied, 1838) and softshell turtles (Amyda cartilaginea Boddaert, 1770) females. This research was carried out for five months starting from September 2013 to January 2014. The methods used in this study were the X-Ray method, boiled bone and Alizarin Red S-Alcian blue staining. The result of research was analyzed descriptively comparatively by direct observation using a digital camera. Based on the results of the study the Red-eared turtle tortoise has a number of 7 cervical vertebrae, $9^{\text {th }}$ vertebrae, sacral vertebrae 1 segment and vertebrae caudalis 27 segments. The anterior and posterior zygapophysis of the cervix elongate thus affecting the limited lateral movement. The thoracic center of the vertebrae adjusts the shape of the carapace. The sacralis vertebrae have 1 centrum segment extending on the lateral side attached to the carapace called the lateral pars, the caudal centrum is short and there is a shortened anterior zygapophysis structure. Whereas softshell turtles have slender and long centrums. The anterior and posterior zygapophysis are smaller and allow the softshell turtles to perform more lateral movements. Centrum vertebrae of the thorachalis have a flat shape adjusting the shape of the carapace. Sacralis vertebrae have 2 centrum and 2 lateral pars extending and meeting each other to form a hole sacralia pelvina, centrum vertebrae caudalis extends and there is a neural spinal structure. Carapace of the red-eared turtle consists of fused pieces. Whereas the carapace in the softshell turtles consists of pieces covered by cartilage. The constituent component of carapace and plastron of the red-eared turtle consists of true bones completely, while the constituent components of the carapace and plastron of softshell turtles consist of true bones and cartilage on the sides and connective between the carapace and plastron.
\end{abstract}

Keywords: Anatomy, Axial skeleton, Red-eared turtle, Softshell turtles

\section{INTRODUCTION}

Reptiles are one of the many types of fauna found in Indonesia. Indonesia ranks third as a country that has the highest reptile wealth in the world. More than 600 types of reptiles are found in Indonesia (Bappenas, 1993). This reptile has long been used, even reptiles themselves have become high-value economic commodities. Reptiles are usually used as pets. However, reptiles are also used for consumption and certain drugs, so that it has developed into various countries in the world. Even in the last two decades, Indonesia has been known as one of the largest exporters of reptiles in the world (Soehartono and Mardiastuti, 2003).

Softshell turtles are reptiles that have a unique body shape with their bodies covered by bones modified from ribs covered by horn substances. The body cover bone consists of two parts, namely the carapace in the dorsal and plastron parts in the ventral part. Softshell turtles do not have teeth, but have strong jaws and are covered with horns (Tjaturadi, 1998). Softshell turtles are a type of reptile belonging to the Testudinata order. The Order Testudinata consists of about 260 species from 75 genera and 13 families. Testudinata includes species that live in the sea, freshwater, and land.
Testudinata represents about $4 \%$ of all types of reptiles in the world (Halliday and Adler, 2000).

According to the head retraction method, softshell turtles are divided into two suborders, namely Pleurodira and Cryptodira. Pleurodira neck bone moves laterally so it can be bent and pulled sideways. While the Cryptodira neck bone moves vertically so that it can be pulled into the shell. Cryptodira suborder can be divided into three superfamily, namely Trionychoidea, Chelonioidea and Testudinoidea. While Pleurodira suborder can be divided into two families, Pelomedusidae and Chelidae (Tjaturadi, 1998).

Species classification can be done by determining the physical character of a species through morphological observations to be described and then grouped into a hierarchy, both taxonomically and phylogenetic relationships. One approach that can be used is to do a descriptive osteology study of structural observations and parts of animal rearing with one another, including the softshell turtles.

Red-eared turtle tortoises (Trachemys scripta elegans) and softshell turtles (Amyda cartilaginea) are one member of the Cryptodira Suborder that has a characteristic difference in length and head-neck movement. Red-eared turtle turtles have a short neck size while turtles tend to be longer. Red-eared turtle turtles cannot move their heads sideways while turtles 
can move their heads to the side, thus attracting researchers to examine more deeply the comparison of the axial skeleton structure of the two softshell turtles species in a study entitled Axial Skeleton Anatomy Structure Red-eared turtle turtles (Trachemys scripta elegans Wied, 1838) and turtles (Amyda cartilaginea Boddaert, 1770) Females.

\section{MATERIALS AND METHODS}

This research was carried out for approximately five months starting in September two thousand thirteen to January two thousand and fourteen at the Integrated Laboratory of UIN Sunan Kalijaga Yogyakarta for the treatment of Alizarin Red S-Alcian Blue method and boiled method. The tool used in this study was a bucket containing water and food as a temporary place for Tortoise and Turtles, surgical instruments, stoves, hacksaw, ovens, glassware, and cameras while the materials used in this study were two Red-eared turtle female and Tortoise two female adult Softshell turtles based on the size of the twenty $\mathrm{cm}$ shell obtained from the PASTY animal market in Bantul Regency, fish as softshell turtles food, alcohol, $\mathrm{KOH}$, acetone, glycerin, chlorophyll, Alizarin Red S-Alcian Blue and distilled water. This study used test animals of adult female Red-eared and adult female Softshell turtles. Adult animals can be identified by the size of the carapace which has reached a length of approximately twenty $\mathrm{cm}$. Observation using X-Ray. To see what is the difference between the return of the Red-eared turtle and the softshell turtles in general, X-Ray is done. The stages according to Rakhmiyati, (2012) are Tortoise and Softshell turtles edited first using chloroform. Tortoise and Softshell turtles are placed on an X-ray machine, then the machine is connected to a computer screen. Furthermore, the species is depicted in the Hewlett-Packard Faxitron model of four thousand eighty thirty $\mathrm{N}$ black and white polaroid radiology units to be able to observe images. Making preparations with Alizarin Red S-Alcian Blue staining. Making Vertebrae Preparations with a Method of Boiling Tortoise and Softshell turtles were anesthetized using chloroform solution, then dissected in the plastron and put into boiling water for three minutes. From anatomical and morphological structures in a comparative descriptive analysis with direct observation using camera digital.

\section{RESULTS AND DISCUSSION}

Based on the morphological observations of the specimens with the objects used were two different types of tortoises, namely the Red-eared turtle (Trachema scripta elegans) as a representative of the hard-shelled tortoise and the female softshell turtles (Amida cartilaginea) as the representative of the turtle soft shells. It can be seen that the red-eared turtle has a hard shell because the carapace is composed of hard bones with a yellowish green color with circular stripes and green patches and has a characteristic red spot on the edge of the head of the eye. Besides that, the plastron part of the Red-eared turtle has circular lines and green-colored spots. The softshell turtles have soft shells, because their carapace is composed of a mixture of true bone and soft bone. In addition, softshell turtles has a jaw that is covered by a sharp beak, its elongated tubular nose resembles a trunk, (Iskandar, 2000).

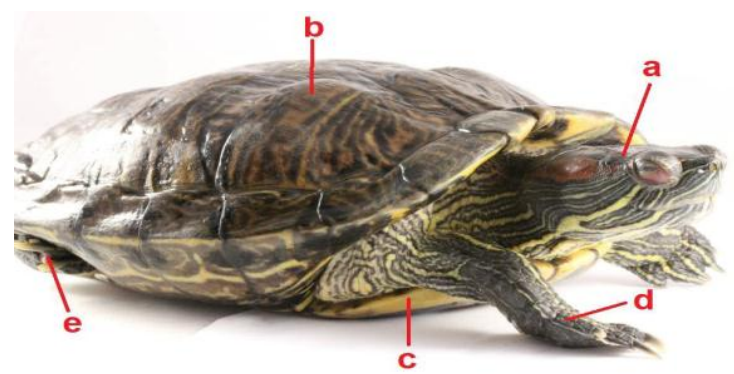

Figure 1. Morphology outside of Red-eared turtle (Trachemys scripta elegans). (a) head, (b) carapacs, (c) plastron, (d) front limbs, (e) hind limb.

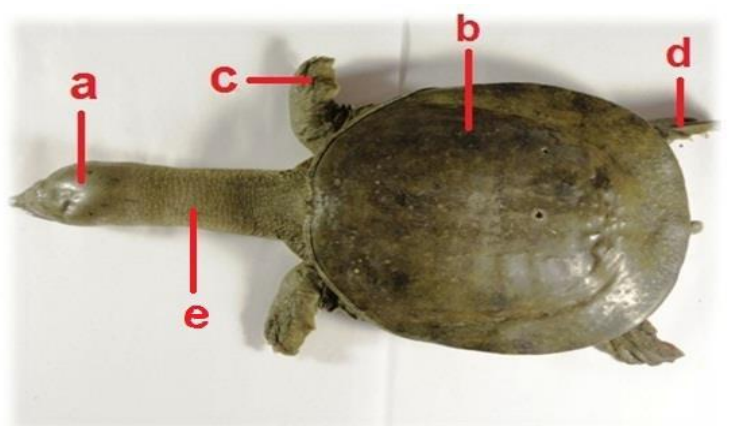

Figure 2. External morphology of softshell turtles (Amida cartilaginea). (a) Head, (b) Carapace, (e) Front limbs, (d) Hind limbs, (e) Neck.

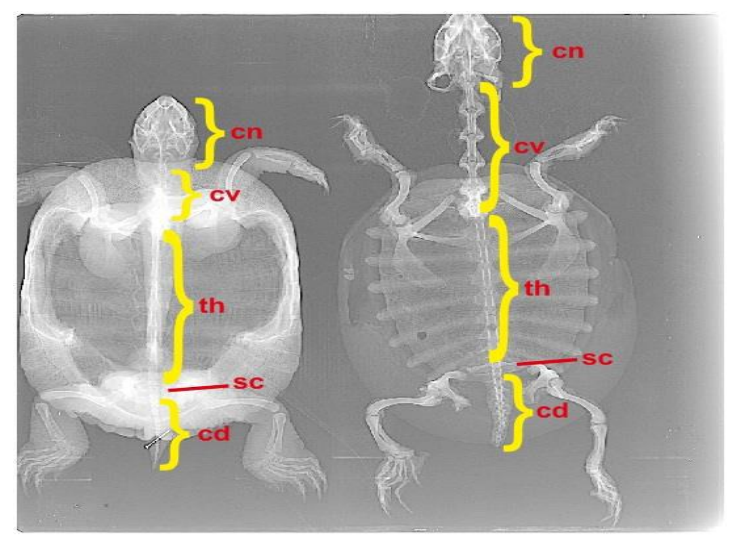

Figure 3. Results of the Skeleton X-Ray of the red-eared turtle (Trachemys scripta elegans) (left) and softshell turtles (Amida cartilaginea) (right). (cn) Cranium, (cv) Cervicalis, (th) Thoracalis, (sc) Sacralis, (ed) Caudalis. 
Based on observations that have been made using the boiled method, it can be seen that the cervical in the Red-eared turtle and the softshell turtles not articulated costae. The first bone that connects with the cranium is the atlas-axis bone. Atlas-axis on the red-eared turtle and softshell turtles has a reinforcing role in connecting the cranium to cervical 1 . Cervical bone red-eared turtle and softshell turtles consists of atlas -axis, cervical $1(\mathrm{CI})$ to cenvical 7 (C7). Here is a picture of $\mathrm{C} 1$ to $\mathrm{C} 7$ from observations.

Figures 4. C1 and C7 Red-eared turtle and softshell turtle, az: anterior zygapophysis, na: neural arch, pz: posterior aygapophysis, tp: transverse process, c: centrum, hy: hypapophysis, ic: intercentrum.

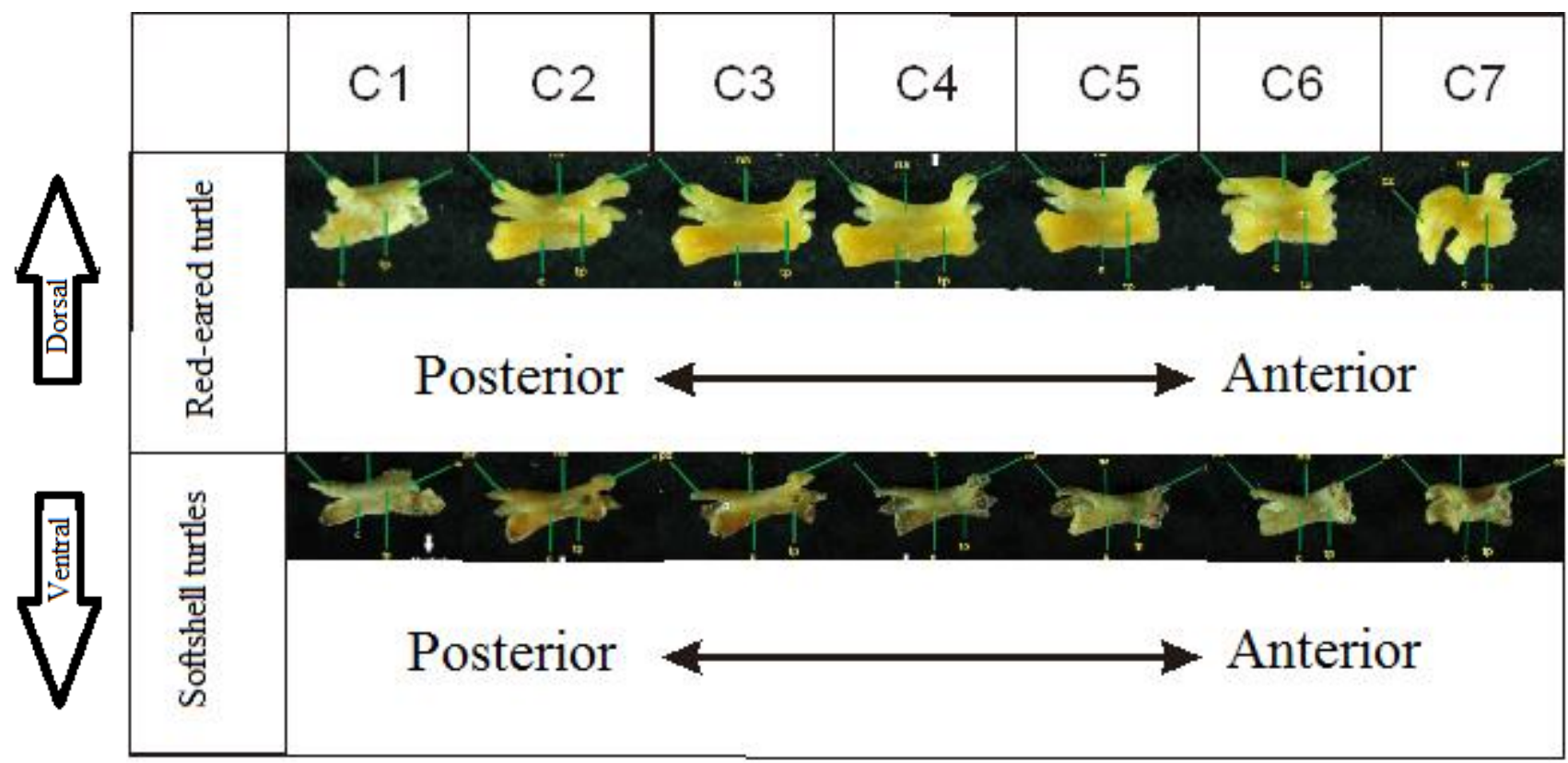

Vertebrae cervicalis brazilia tortoise and softshell turtles each segment has centrum as a buffer and processus, as an amplifier and a place to attach the brain. To several processes in the vertebrae, among others, Zygapophysis consists of anterior zygapophysis which is an anterior protrusion of the arcus, neuralis with facing articulation facies dorsomedial and postzygapophysis which are posterior protrusions of the arcus neuralis with facies articulation facing the ventrolateral. The main function of the tortoise and softshell turtles vertebrae cervicalis is to retract (facilitate) and facilitate the flexibility of head movements and as a link between cranium and columna vertebralis. Red-eared turtle have hygapophysis function as a place to attach the transversal hypapophysis muscle and connect to the subvertebral musculature system and limit curved neck movements to the ventral.

The vertebrae thorachalis in red-eared turtle have 9 vertebrae segments which are modified into one with carapace and plastron. The carapace section of the redeared turtle has nukhal pieces as the first piece of back shield and then continues with 5 vertebral pieces flanked by 4 pairs of costal pieces and 11 pairs of marginal pieces on the lateral side and the tip of the carapace of the supracaudal puck (1 pair) which indicates parallel to the vertebrae caudalis. Meanwhile, the Red-eared turtle plastron converges with the carapace in the lateral part. There are several pieces of the plastron, a pair of gular pieces, a pair of humeral pieces, a pectoral chip (I pairs), abdominal (I pair), a femoral chip (1 pair), and an anal chip (1 pair).

In the softshell turtles the part of the carapace and the plastron is composed of cartilage. Vertebrae thorachalis turtles numbered 10 segments. Nukhal pieces on the carapace of the turtles have a wider and larger structure. Then 8 neural pieces are parallel to the line of the spine flanked by 7 pairs of pleural pieces that build carapace and there are pigal pieces at the end. Whereas in the plastron part there is a pair of curved epiplastron bones, then connected with an entoplastron bone resembling a boomerang, the hioplastron which connects with the carapace and the end of the bone is a pair of xiphiplastrons.

The structure of the vertebrae sacralis in red-eared turtle and softshell turtles has different structures. Vertebrae sacralis Red-eared turtle has a centrum that extends on the lateral side attached to the carapace which is pars lateralis to the carapace and has only 1 segment. While the vertebral sacralis structure of the softshell turtles has 2 centrums and 2 pars lateral 
extending and meeting each other to form a hole sacralia pelvina.

The structure of the vertebrae caudalis in red-eared turtle and turtles has different structures. Red-eared turtles have a short centrum, but have a large number of segments, namely 27 segments, allegedly greatly affecting the movement of the tail. While the structure of the vertebrae caudalis turtles have a long centrum and there are only 11 vertebrae caudalis segment.

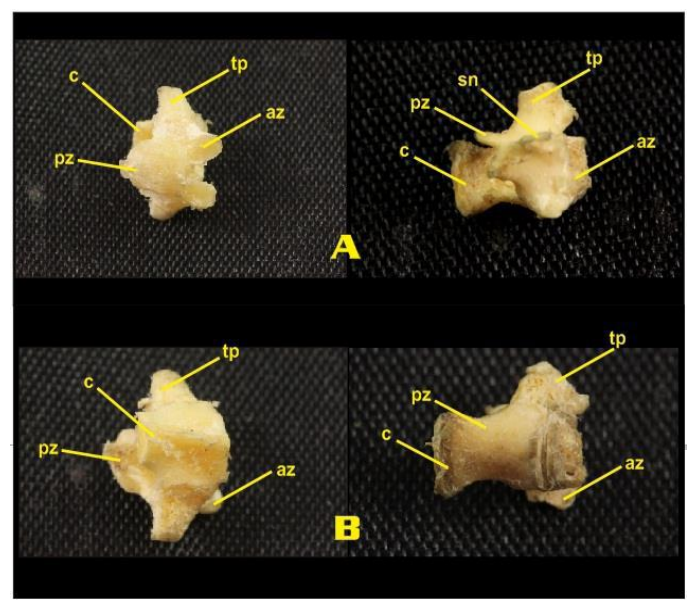

Figure 5. Vertebrae caudal bones Red-eared turtle (Trachenys scripta elegans) (left) and softshell turtles (Annda cartilaginea) (right) females. A: Dorsal, B: Ventral c: Centrum, pz: posterior zygapophysis, az: anterior zygapophysis, tp: transverse processus, sn: spima meuralis

The observation of Alizarin Red S-Alcian Blue staining was also done on red-eared turtle and softshell turtles to find out the bone structure. Vertebrae of the Red-eared turtle consisting of vertebrae cervicalis, the of vertebrae thoracal, the vertebrae sacralis, the vertebrae caudal are completely red, indicating that the vertebrae are composed of true bones. The carapace and plastron of the Red-eared turtle also show red color, meaning that the carapace and plastron tortoise are composed of true bones. Whereas the vertebrae in the softshell turtles are red as in the Red-eared turtle, but carapace and plastron softshell turtles the inner is red and the outer part is brownish blue. The blue color shows that the carapace of the softshell turtles is coated with cartilage.

\section{CONCLUSIONS}

Based on the results of the study, it can be concluded that:

1. Red-eared turtle female has seven vertebrae of the vertebrae, nine vertebrae of the thorachalis, sacral vertebrae of one segment and vertebrae of the caudalis of twenty-seven segments. Centrum vertebrae large Red-eared turtle with anterior and posterior zygapophysis in the cervical dilate and elongate, affecting the lateral movement limitations. Whereas female softshell softshell turtles has the number of the seven cervical vertebrae, the ten thoracal vertebrae, the sacral vertebrae of the two segments and the vertebrae caudalis eleven. Centrum verebrae small softshell turtles with anterior and posterior zygaphophysis in the thin and short cervical.

2. The carapace of the Red-eared turtle consists of fused pieces. Whereas the softshell turtles carapace consists of pieces wrapped in cartilage. The plastron consists of pieces that are a pair of epiplastron bones, an entoplastron bone, a pair of hyoplastron bones and a pair of hypoplastron bones and a pair of xiphiplastron bones. The carapace and plastron of the Red-eared turtle are made up of true bone completely, whereas the carapace and the plastron of the softshell turtles are composed of true bones and cartilage on the sides and the link between the carapace and the plastron.

\section{ACKNOWLEDGMENTS}

The author would like to thank to the management of apprenticeship program of faculty of science and technology for guidance during the research, to the management of biology, medicine and natural product chemistry \& kaunia journal for assistance in paper writing.

\section{REFERENCES}

Bappenas. 1993. Biodiversity Action Plan for Indonesia. Ministry Of Development Planning/ National Development Planning Agency. Jakarta.

Halliday, T. dan K. Adler. 2000. The Encyclopedia of Reptiles and Amphibians. Facts on File Inc. New York.

Iskandar, D. T,. 2000. Kura-kura Dan Buaya Indonesia Dan Papua Nugini. PAL Media Citra. Bandung

Rakhmiyati. 2012. Struktur Anatomi Dan Histologi Ekor Regenerat Dan Ekor Asli Cicak Tembok (Hemidactylus frenatus Schlegel, 1836). [Skripsi]. Yogyakarta : UIN Sunan Kalijaga

Soehartono, T. dan A. Mardiastuti. 2002. Pelaksanaan Konvens CITES di Indonesia. Japan Internasional Cooperation Agency (JICA). Jakarta.

Tjaturadi, Burhan. 1998. Perilaku Perkembangbiakan kura-kura Cuora amboinensis (Bell.) dalam kandang. [Skripsi]. Yogyakarta : UGM. 